\title{
IV. La Garantía Individual De Libre Portación De Armas De Fuego En EI Contexto Del Marco Constitucional, Legal Y Social De Nuestro País.
}

\author{
Miguel PEREZ RENDÓN
}

Sumario I. Introducción. II. Referente Histórico. III. Significado de la Garantía Individual Seleccionada. IV. La Libertad De Portación De Armas Como Reconocimiento Del Estado A La Autodefensa. V. Análisis De La Ley Federal De Armas De Fuego Y Explosivos Vigente. VI Aspectos Sociopolíticos. VII. Conclusiones

\section{INTRODUCCIÓN.}

El objeto del presente ensayo, es analizar la vigencia y/o pertinencia del artículo décimo de nuestra Carta Magna el cual contiene la garantía individual relacionada con la libre posesión de armas de fuego por parte de los habitantes de los Estados Unidos mexicanos. Este análisis se llevara acabo desde dos puntos vertientes uno eminentemente jurídico y uno ubicado en el entorno social donde se aplica la norma.

A lo largo de este ensayo, primeramente, expondremos el referente histórico que dio origen a la creación de esta garantía de libertad y para ello expondremos los antecedentes relacionados desde la monarquía española hasta lo que plasmó el constituyente de 1917 , claro esta explicando cada uno de los cambios que dio esta garantía en este largo periodo.

Asimismo, posteriormente se podrá observar como se desagrega este precepto para poder ubicar los 3 supuestos que regula detalladamente y con ello poder entender sin lugar a dudas el alcance que tiene esta garantía en los habitantes del territorio nacional. Este análisis se realizara con el apoyo de diversos autores relacionados con el estudio en este ramo.

Finalmente, una vez que se hay comprendido el significado y alcance del artículo décimo constitucional, plantearemos los factores sociales y políticos que lo rodean con el fin de poder cuestionar la pertinencia de esta norma en el desarrollo del México Contemporáneo.

\section{DESARROLLO DEL TEMA.}

El derecho que el estado reconoce a los miembros de una sociedad para que puedan poseer y portar armas, tienen sustento sin duda en una larga tradición histórica nacional y mundial, subsistiendo actualmente, sin embargo para que la protección de este derecho sea legitima primeramente debe estar respaldada por la aprobación social y claro esta refrendada en nuestra Carta Magna para poder llevar a cabo su estricto cumplimiento.

El objetivo del presente ensayo es llevar a cabo el cuestionamiento sobre la pertinencia de esta garantía en el contexto actual, estudiar los factores sociales que implican su cumplimiento o su falta de aplicación o seguimiento y para ello necesariamente tendremos que desentrañar primeramente el contexto histórico en el cual fue creada, llevar a cabo el análisis jurídico de ésta garantía, de tal forma que nos permita conocerla y una vez que se cuenten con estas herramientas poder cuestionarla para poder evaluar su pertinencia o su reforma. 


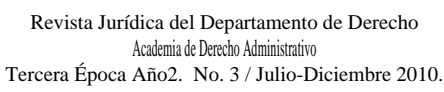

Pues bien, empecemos primeramente a comprender los antecedentes que se relacionan con la garantía individual consagrada en nuestra Constitución Política, para después entender su significado y finalmente su análisis social.

\section{REFERENTE HISTÓRICO.}

Sin duda, para poder entender en este ensayo la forma en que se concibió a la garantía individual relacionada con la libre portación de armas de fuego en nuestro país, debemos señalar el recorrido histórico que permito su gestación, ya que su historia nos permitirá conocer la vigencia y la pertinencia del precepto, aprender de él, visualizar sus errores y contexto en el cual fue creada para finalmente concluir si es aplicable o no a nuestra sociedad mexicana contemporánea.

En el Caso del artículo 10 constitucional, este tiene su antecedente en la Constitución Política de la monarquía española, promulgada en Cádiz en 1812 la cual disponía lo siguiente:

\section{"En la junta parroquial ningún ciudadano se presentará con armas"”}

Sin embargo, en México no fue hasta 1824 donde fue acogida esta garantía mas no por la Constitución Federal, sino por un bando de gobierno que prohibía la portación de armas sin contar con licencia para ello, salvo en los casos que se requiriese para un empleo.

En la Constitución Política de 1857 se reconoce este derecho ya en el rango constitucional, dando la potestad a los hombres de tener derecho a poseer y portar armas para su seguridad y legítima defensa, señalando las armas prohibidas y las penas que incurren en caso de no ser obedecido este ordenamiento.

En 1981 el entonces presidente Benito Juárez promulgó un decreto a través del cual ordenaba a los habitantes de la república entregar todas las armas que tuviera en su poder, lo que ocurrió a la par de una posible invasión extranjera de los países de Inglaterra, Francia y España ${ }^{9}$.

Finalmente en la Constitución de 1917 se estableció este artículo tal cual lo conocemos en la Constitución Vigente, solo que antes se sujetaba a los reglamentos de policía para su reglamentación y hoy en día para ello se remite a la ley federal.

El texto hoy vigente establece lo siguiente:

Artículo 10.- Los habitantes de los Estados Unidos mexicanos tienen derecho a poseer armas en su domicilio, para su seguridad y legítima defensa, con excepción de las prohibidas por la ley federal y de las reservadas para el uso exclusivo del Ejército, Armada, Fuerza Aérea y Guardia Nacional. La ley federal determinará los casos, condiciones, requisitos y lugares en que se podrá autorizar a los habitantes la portación de armas.

Mucho se ha hablado de llevar a cabo reformas constitucionales a este ordenamiento, ya que en un país de 103 millones de habitantes con casi dos millones de kilómetros cuadrados, solamente en el Distrito Federal puede tramitarse un permiso extraordinario para la adquisición de armas en la Dirección General del Registro Federal de Armas de Fuego y Explosivos y el poder adquirir un arma en la Unidad de

\footnotetext{
${ }^{8}$ Véase en artículo 56 Constitución Política de la Monarquía Española. promulgada en Cádiz a 19 de marzo de 1812 , por Fernando VI, la cual se puede consultar en la siguiente dirección electrónica: http://www.cadiz2012.es/images/secciones/constitucion/cons_1812.pdf

${ }^{9}$ Burgoa O. Ignacio, Las Garantías Individuales, Editorial Porrúa, Séptima edición, 1994. P. 391

$$
\sim 21 \sim
$$
}




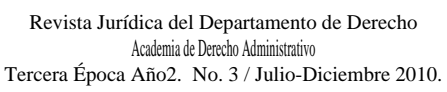

Comercialización de Armas y Municiones se ha vuelto un trámite burocrático muy difícil por lo que se tiene la necesidad imperiosa de desconcentrar estas funciones a los Estados ${ }^{10}$.

En este mismo sentido se pronuncia el Mtro. Ignacio Burgoa al decir en su libro dedicado a la compresión de las Garantías Individuales que se necesita "una reforma del artículo 10 constitucional, mediante la cual el Congreso de la Unión, acorde a las circunstancias imperantes en el país, determine los casos, condiciones y lugares en que podrán otorgarse permisos de portación de armas, así como las autoridades competentes para expedirlos"11.

Sin embargo para poder entender, la validez de las voces que solicitan reformas como la mencionada en el párrafo anterior o de otras que reclaman otro tipo de reformas debemos primeramente comprender el significado de esta garantía individual, labor que a continuación se desarrolla.

\section{SIGNIFICADO DE LA GARANTÍA INDIVIDUAL SELECCIONADA.}

En este apartado nos abocaremos a desarrollar el primer de objetivo de este ensayo que es el poder entender correctamente el significado de este artículo mediante la interpretación jurídica por lo que resulta importante reconocer básicamente lo siguiente.

La garantía individual que consagra el derecho de portación de armas reconoce a los miembros de una sociedad para que puedan poseer y portar armas a nivel constitucional como parte de las garantías que se deben de proteger en el individuo por parte del estado.

Para el análisis de esta garantía individual hay que examinar primeramente el artículo constitucional que la establece independientemente de que mas adelante en este ensayo se analice el aspecto sociopolítico de su reconocimiento.

Para poder hacer el estudio del artículo décimo constitucional seguiremos el esquema que propone el Dr. Alejandro Concha Cantú en su colaboración de la Constitución Política Comentada. Este autor nos indica que habría que desagregar este ordenamiento en tres supuestos que, aunque están interrelacionados, deben ser analizados por separado.

El primero de ellos lo identificamos al señalar el artículo décimo lo siguiente:

...Los habitantes de los Estados Unidos mexicanos tienen derecho a poseer armas en su domicilio, para su seguridad y legítima defensa ${ }^{12}$...

En este contexto se establece de alguna forma una autorización a los mexicanos para poseer armas a partir de la necesidad de las personas de protegerse y defenderse contra cualquier tipo de agresión que se de contra su vida o patrimonio personal.

Con este párrafo se encuentra íntimamente relacionado con lo establecido por el artículo 17 Constitucional que establece:

Artículo 17.- Ninguna persona podrá hacerse justicia por sí misma, ni ejercer violencia para reclamar su derecho... Toda persona tiene derecho a que se le administre justicia por Tribunales... Las leyes federales y

\footnotetext{
${ }^{10}$ Periódico Excelsior, 27 de febrero de 2006.

${ }^{11}$ Burgoa O. Ignacio, Op. Cit, p. 392

${ }^{12}$ Constitución Política de los Estados Unidos Mexicanos, artículo 10. Pág. 10
} 
Revista Jurídica del Departamento de Derecho Academia de Derecho Administrativo

Tercera Época Año2. No. 3 / Julio-Diciembre 2010.

locales establecerán los medios necesarios para que se garantice la independencia de los tribunales y la plena ejecución de sus resoluciones ${ }^{13}$.

Como podemos ver en este artículo 17 se establece que la seguridad de las personas es una función exclusiva de las instituciones de gobierno por lo que los individuos no deberían en este supuesto protegerse o defenderse uno contra otro sin tener como mediador a la justicia gubernamental impartida a través de sus instituciones. Sin embargo el poseer armas lo presentan evidentemente en el artículo 10 como un derecho eminentemente de defensa y protección en caso extremo de que se ocupase la seguridad o legitima defensa, por lo que para prevenir la subjetividad a la que se pudiese prestar estos conceptos, el mismo Estado Mexicano ha creado leyes límites y requisitos a la posesión de armas plasmados en diversas leyes secundarias ${ }^{14}$.

Entre los requisitos mas destacados podemos mencionar los siguientes:

- Solo pueden poseerse armas en los domicilios reconocidos por los particulares y,

- Que no sean armas destinadas a las funciones de seguridad pública.

Como vemos de alguna forma en este primer supuesto del artículo 10 constitucional se establece como una medida de excepción a lo establecido por el 17 del mismo ordenamiento. Las razones las veremos más adelante cuando veamos las condiciones sociales, económicas y políticas que rodean la creación de este derecho.

El segundo supuesto que se plasma en este artículo es el siguiente:

...con excepción de las prohibidas por la ley federal y de las reservadas para el uso exclusivo del Ejército, Armada, Fuerza Aérea y Guardia Nacional...

En opinión del Dr. Alejandro Concha Cantú esta enunciación se establece para dejar claro que el Estado Mexicano es el único poseedor legítimo del uso de la fuerza pública, ya que cuenta con el derecho absoluto de poseer armas a través de sus instituciones de seguridad. Nuestra Constitución, en el artículo 10 se refiere al Ejercito, Armada, Fuerza Aérea y Guardia Nacional, sin embargo a partir de 1994 - señala el Dr. Concha Cantu - en 1994 se incorpora el concepto de seguridad pública en el artículo 21 de la constitución estableciendo señalando las coordinaciones a las que debe incorporarse este sistema de seguridad en la defensa al interior y exterior del pais ${ }^{15}$ porque lo que las se amplia el rango de autoridades poseedoras de la fuerza pública nacional.

Como se puede apreciar a través de este supuesto se pretende dejar claro que el monopolio del uso de la fuerza pública se encuentra en el Estado para evitar que una persona ejerza violencia contra otra.

De esta forma, el monopolio de la violencia ${ }^{16}$, está reservado a los poderes públicos, que la deben de administrar en un escrupuloso respeto a la ley de allí el que sea exclusivamente el Estado el que pueda elegir el armamento que ocupe para garantizar el respeto a la fuerza pública, facultad que no tiene el ciudadano, salvo los casos de excepción mencionados.

\footnotetext{
${ }^{13}$ Ídem. Pág. 12

${ }^{14}$ Ley Federal de Armas de Fuegos y Explosivos, Código Penal Federal y local, entre otros.

${ }^{15}$ Constitución Política de los Estados Unidos Mexicanos Comentada, Porrúa, 1995. p. 99 y véase artículos 31, 35, 73, 89 y 129 de la Constitución Política Mexicana.

${ }^{16}$ Para mas información de este concepto léase interesante artículo publicados por Manuel Delgado en La Haine, el cual se puede consultar vía Internet en la siguiente dirección: http://lahaine.org/index.php?blog=2\&p=9249
}

$$
\sim 23 \sim
$$


Revista Jurídica del Departamento de Derecho Academia de Derecho Administrativo

Tercera Época Año2. No. 3 / Julio-Diciembre 2010.

El tercer y último supuesto que plantea este artículo lo podemos entender como una ventana abierta que deja el Constituyente para determinar aquellos casos y condiciones bajo las cuales el individuo podrá poseer armas, ya que esto se establecerá en los ordenamientos federales que se expidan para ello.

Este último supuesto establece:

...La ley federal determinará los casos, condiciones, requisitos y lugares en que se podrá autorizar a los habitantes la portación de armas...

Sin duda, a mi forma de ver es una puerta abierta mediante la cual el estado puede reducir o ampliar el nivel de portación de armas para uso individual, así como también permite relacionar las actividades fuera a lo relacionado con la legítima defensa en las cuales se puede usar armamento como es el caso de las diversas actividades deportivas relacionadas con esta materia.

\section{LA LIBERTAD DE PORTACIÓN DE ARMAS COMO RECONOCIMIENTO DEL ESTADO A LA AUTODEFENSA.}

Ahora bien, con el hecho de garantizar como derecho a los individuos la portación de armas independientemente de las características que tengan estas, si bien se reconoce por parte de Estado Mexicano la incapacidad de brindar de manera absoluta la seguridad personal, también es cierto lo dicho por el Dr. Alejandro Concha Cantú al momento de decir que si bien es cierto que existe esta incapacidad, también lo es que es existen situaciones de imprevisibilidad e incertidumbre que impiden a cualquier autoridad su presencia de manera oportuna y llevar a cabo su función protectora por lo que se faculta al individuo a estar preparados para su autodefensa ${ }^{17}$.

Este reconocimiento de la autodefensa se encuentra basado para el autor en mención en el principio de legitimidad sobre el que se sustenta este derecho individual de poseer armas. Sin embargo esta autodefensa reconocida es limitada por el artículo 17 Constitucional, es decir, es aceptado esta autodefensa solamente en los criterios de excepción plasmado en el orden jurídico, ya que si no fuese así se pudiere convertir en un delito penado.

Sin embargo para algunos autores, el margen de actuación que tenga el individuo reconocido como autodefensa se encuentra directamente proporcional con el nivel de eficiencia en la seguridad pública que puede proporcional cualquier Estado.

Partiendo de esta idea, el estado se ha flexibilizado en la aplicación de las responsabilidades que pueden tener los ciudadanos al no cumplir estrictamente con la normatividad vigente que regula la portación de armas en pro de asegurar que la autodefensa cuando fuese justificada no fuese penada y esto lo ha realizado a través del poder a través de sus tesis y para muestra señalaremos la siguiente:

ARMAS DE FUEGO, PORTACIÓN DE. Independientemente de que la portación de armas sin licencia no puede constituir un ilícito penal, esa portación tampoco puede integrar falta administrativa, si la misma la realizaba en el domicilio propio.

\footnotetext{
${ }^{17}$ Constitución Política de los Estados Unidos Mexicanos Comentada, Op. Cit. p. 99
}

$$
\sim 24 \sim
$$


Revista Jurídica del Departamento de Derecho Academia de Derecho Administrativo

Tercera Época Año2. No. 3 / Julio-Diciembre 2010

Amparo penal directo 313/53. Por acuerdo de la Primera Sala, de fecha 8 de junio de 1953, no se menciona el nombre del promovente. 15 de febrero de 1954. Unanimidad de cuatro votos. Ausente: Luís Chico Goerne. La publicación no menciona el nombre del ponente.

Instancia: Primera Sala. Fuente: Semanario Judicial de la Federación. Época: Quinta Época. Tomo CXIX. Tesis: 1a. Página: 997. Tesis Aislada

\section{ANÁLISIS DE LA LEY FEDERAL DE ARMAS DE FUEGO Y EXPLOSIVOS VIGENTE.}

Tanto la ley Federal de Armas de Fuego y Explosivos expedida por el entonces Presidente Luís Echeverría Álvarez en 1972 y reformada en algunas ocasiones por el gobierno de Vicente Fox, se encarga de regular con detalle todo lo relativo a la posesión y portación de armas, así como su fabricación y comercio y en esta ley se establecen las siguientes directrices para la permisibilidad de relacionada con esta materia.

En esta Ley de Armas de fuego se establece en su artículo 4 que corresponde al Ejecutivo de la Unión por conducto de las Secretarías de Gobernación y de la Defensa Nacional el control de todas las armas en el pais ${ }^{18}$, por lo que a través de este lineamiento pretende tener el control total del armamento legal que se encuentre en el país, y para ello lleva a cabo la creación de un Registro Federal de Armas.

La finalidad mantener este registro sin duda es controlar la posesión y portación de las armas en los individuos y tener la certeza de que estas no estén prohibidas por la Ley o sean de las reservadas para el uso exclusivo del Ejército, Armada y Fuerza Aérea ${ }^{19}$. Con lo anterior quizás pretenda garantizar que la fuerza del Estado sea la más fuerte y que se pueda imponer ante cualquier intento de alteración del orden público o menoscabar la tranquilidad nacional.

El Estado Mexicano, sin embargo en el reconocimiento de la autodefensa antes mencionada establece la posibilidad de poseerse o portarse armamento de una forma limitada, solamente que limita los términos y condiciones a través del artículo 9 de la Ley en mencionada, definiendo la cantidad y características de armas que garanticen su autodefensa ${ }^{20}$.

Ahora bien, para el Gobierno Mexicano el armamento no solo se considera como un medio de defensa ante situaciones imprevistas que atenten contra la integridad del individuo, sino que permite la portación de armas de diversos calibres para actividades de recreo o deportivas como lo son las de tiro o cacería $^{21}$, sin embargo estas nunca serán las que se encuentran consideradas como armas, municiones para el uso exclusivo del Ejército, Armada y Fuerza aérea ${ }^{22}$.

En este orden de ideas, consientes las Instituciones Mexicanas de necesidad de armar en casos especiales a los habitantes del territorio nacional permiten el uso de estas para garantizar la multicitada autodefensa, sin embargo en la Ley Federal de Armas de Fuego establecen terminantemente que les queda prohibido a los particulares asistir armados a manifestaciones y celebraciones públicas, a asambleas deliberativas, a juntas en que se controviertan intereses, a cualquier reunión que, por sus fines, haga previsible la aparición de tendencias opuestas y, en general, a cualquier acto cuyos resultados

\footnotetext{
${ }^{18}$ Ley Federal de Armas de Fuego y Explosivos, Op. Cit. página 1.

19 Ídem. Página 2.

${ }^{20}$ Ídem. Articulo 9, p. 3.

${ }^{21}$ Ídem, Artículo 10, p. 4

22 Ídem. Artículo 11, p. 4.
} 


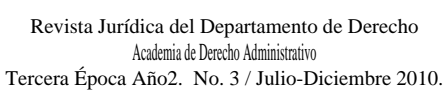

puedan ser obtenidos por la amenaza o el uso de las armas ${ }^{23}$, ya que si esto se permitiera se alentara primeramente la creación de movimientos sociales armados que constantemente serían considerados una amenaza al statu quo gubernamental.

Finalmente, con el objetivo de poder localizar oportunamente el armamento inventariado en el país se le ha exigido al particular a través del artículo 15 de la Ley Federal de Armas de Fuego, específicamente en su artículo 15, el poseer armas para la seguridad y defensa legítima en el domicilio del registrado exclusivamente sin que este se entienda el fiscal, el automóvil, etc. como lo veremos a continuación:

\section{ASPECTOS SOCIOPOLÍTICOS.}

Ahora bien, una vez comprendido el significado que tiene esta multicitada garantía con el análisis de este ordenamiento y su ley reglamentaria, pasaremos a desarrollar nuestro segundo objetivo en este ensayo, el cual a mi forma de ver se presenta como mas importante ya que nos permite ver el entorno social donde se ubica esta garantía y sus posibles repercusiones de esta índole.

En la actualidad todos los países del mundo tienen armas, registradas algunas y otras no, y una gran cantidad de esas naciones están en conflictos internos armados, en los cuales no es la excepción nuestro país con el levantamiento de ejércitos insurgentes como lo es el EZLN y EPR sin mencionar el problema actual que se vive con el narcotráfico a nivel mundial.

Sin embargo, en países como el nuestro, no existen comercios públicos para la compra y venta de las armas para los ciudadano, ya que esta se hace a través de la Secretaría de Defensa Nacional, no es el caso de lo que sucede en los Estados Unidos donde hay una gran cantidad de comercios que se dedican a esta compra y venta. Para México esto ha generado que exista un problema de comercio clandestino con este país vecino, lo que viene a constituir un gran negocio por parte de grandes mafias también armadas.

Cada vez son más las muertes atribuidas a disparos de armas de fuego, pistolas, armas automáticas o semiautomáticas van en aumento. En Estados Unidos por ejemplo se estima que entre 650,000 y 2 millones de armas pueden estar en manos de criminales por toda la nación ${ }^{24}$.

De lo anterior se desprende la posibilidad de existencia de un grupo de delincuentes que están en posibilidad de ganar un enfrentamiento contra las autoridades.

Particularmente en el Estado de Sonora se ha considerado como una de las zonas mas propicias para el tráfico de armas de fuego por parte de los cárteles de la droga y las organizaciones delictivas, según un informe de la Procuraduría General de la República (PGR)25.

Según la revista Dossier Político, los estados de Baja California, Sinaloa y Sonora son los que presentan el mayor número de investigaciones por posesión, tráfico y acumulación de armas de fuego de uso exclusivo del Ejército y de acuerdo con los reportes de la PGR, en estas tres entidades se ha realizado el mayor número de aseguramientos de armas ilegales en todo el país.

Asimismo, señala ${ }^{26}$ que la venta de pistolas, rifles de asalto o armas de precisión, representan el segundo negocio de mayor beneficio económico para la delincuencia organizada. Las estadísticas oficiales

\footnotetext{
${ }^{23}$ Ídem. Artículo 36, p. 10.

${ }^{24}$ García Ramírez, Efraín. Análisis jurídico de los delitos contemporáneos en la Ley de Armas de Fuegos y Explosivos, 4 edición, Editorial SISTA, p. 132.

${ }^{25}$ http://www.dossierpolitico.com/vernoticiasanteriores.php?artid=16103\&relacion=dossierpolitico, p.1.
} 
señalan que el $\mathbf{8 0 \%}$ de los delitos considerados como graves (principalmente relacionados con la delincuencia organizada), se comente con violencia y en posesión de un arma de fuego ${ }^{27}$.

Como es posible ver si bien el permitir que la gente tenga armas constituye una forma de seguridad personal en virtud del reconocimiento tácito que por parte de la autoridad de su insuficiencia para proteger a la ciudadanía también sin duda esta permisión en los hechos excede lo limites establecidos por la ley en virtud de la cantidad de armas sin permiso que existen a nivel nacional.

A medida que las armas fueron haciéndose más potentes, las victimas llegaron a ser más numerosas. Las piedras, lanzas y flechas fueron sustituidas por armas de fuego y bombas. Y de aniquilar a uno, se pasó a decenas y después centenares, hasta llegar a millares y así hasta cientos de miles ${ }^{28}$.

Lo señalado anteriormente, es quizá la respuesta o sustento sociológico que da fundamento a la restricción de uso de armas en la ciudadanía mexicana plasmado en la garantía individual que se comenta, ya que con ello se pretende evitar en forma definitiva el tráfico y uso de armas para cometer una gran cantidad de ilícitos de forma violenta, lo que repercute obligadamente en la paz y seguridad nacional.

Ahora bien si nuestra finalidad en este ensayo primeramente se concreta explicar de manera clara el contenido del artículo 10 constitucional, es también entender el contexto histórico en que fue creado y como se desarrollo en el entorno actual.

Debido al mercado negro que existe en México, no se sabe cuantas armas de fuego hay en el país, siendo que la venta de armas es generada por elementos de corporaciones policíacas, además del gran contrabando clandestino que existe en pequeña escala y gran escala, principalmente de armamento que proviene de los Estados Unidos de América.

Muchas de las Armas que usan los narcotraficantes y guerrilleros en México, son procedentes de nuestro vecino del Norte como habíamos dicho, pero también hay un gran número que provienen de América Central, las cuales fueron vendidas por militares retirados o por guerrilleros después de los movimientos armados.

Sin duda, es fácil de conseguir armas de fuego en los Estados Unidos de América, ya sea legal o ilegalmente por lo que muchas de estas son fáciles de enviar a México, teniendo como consecuencia que una gran parte de la población en nuestro país se encuentre armada, sin llenar los requisitos de Registro ante la Secretaría de la Defensa Nacional, por lo que lo establecido por el artículo décimo constitucional si bien es una forma teórica de controlar el acceso de las armas a los ciudadanos, la realidad nos muestra otro escenario donde las autoridades poco pueden hacer contra la clandestinidad, lo que al sumarse como los grandes problemas nacionales se culmina con violencia en el orden público nacional.

La naturaleza del legislador al momento de elaborar este artículo constitucional, sin duda fue suplir, como ya se dijo antes, su imposibilidad de cubrir todos los escenarios que atenten contra la seguridad nacional y no fue como en el Caso de los Estados Unidos que en este rubro en su constitución americana estableció el libre armamento ciudadano como un medio de tener preparada a la ciudadanía como milicia para defender las libertades públicas ${ }^{29}$.

\footnotetext{
${ }^{26}$ Ibíd. p.2.

${ }^{27}$ En Sonora en el 2007 el Ministerio Público inició 644 averiguaciones previas por la violación a la Ley Federal de Armas y Explosivos. Ibíd. 2.

${ }^{28}$ García Ramírez, Efraín. Op. Cit., p. 132

${ }^{29}$ Montiel y Duarte Isidro, Estudios sobre Garantías Individuales, Editorial Porrúa, p 311.
} 
Revista Jurídica del Departamento de Derecho Academia de Derecho Administrativo

Tercera Época Año2. No. 3 / Julio-Diciembre 2010

Sin embargo, la buena intención del legislador actualmente no alcanza para controlar el tráfico clandestino de armas en nuestro país, ni tampoco alcanza para poder regular el armamento registrado a nivel nacional por lo que es conveniente hacer ajustes quizá no al precepto constitucional, si no a las competencias que regulan esta materia y a sus leyes reglamentarias, ya que estas no son suficientes para establecer programas para desarmar a ese sector de la población que mantiene estos artefactos nocivos de manera clandestina para cometer delitos y no para cumplir con la naturaleza del artículo décimo que a mi forma de ver es, como ya se ha insistido a lo largo del presente documento, la autodefensa del ciudadano frente a los acontecimientos que la seguridad pública no puede cubrir por razones especiales.

\section{Conclusiones.}

Como hemos podido apreciar a lo largo de este trabajo, el derecho de poseer, portar y hasta comercializar con armas no tiene restricciones o estas son bastante reducidas, como sucede en otros países, particularmente en los Estados Unidos. Ya que si bien existe una normatividad estricta en materia de portación y comercialización de armas de fuego, la realidad nos muestra que la norma es superada en gran medida por grupos o movimientos insurgentes, la delincuencia organizada o mas aún por los particulares que realmente la ocupan para autodefensa pero ante la burocracia que encierra la legal portación de armas de fuego, mejor optan por dejar al margen el tramite de licencias y permisos, lo que finalmente ocasiona que el estado no tenga el control sobre el armamento que circula por territorio nacional.

No es que no exista regulación sino que se mantiene al margen de la realidad haciéndola obsoleta y marginada, lo que sin duda puede acarrear serios problemas de criminalidad y de inestabilidad social.

Existen diversos candados legales que permiten tener control legal de el tipo de armas permitidas, ya que el las leyes reglamentarias, la Secretaría de Defensa y de Gobernación establecen límites a la "libre" portación y posesión de estos artefactos, mas sin embargo la carencia de programas que den seguimiento a las armas permitidas en territorio nacional, el centralismo en el otorgamiento de permisos y la creciente inseguridad en el país fomenta la comercialización clandestina de armamento, la criminalidad y la alteración del orden social.

\section{BIBLIOGRAFÍA}

Constitución Política de los Estados Unidos Mexicanos

Constitución Política de la Monarquía Española de 1812.

Ley Federal de Armas de Fuegos y Explosivos.

Código Penal Federal.

Burgoa O, Ignacio, Las Garantías Individuales, Porrúa, 1994.

García Ramírez, Efraín. Análisis jurídico de los delitos contemporáneos en la Ley de Armas de Fuegos y Explosivos, 4 edición, Editorial SISTA, 1997

Montel y Duarte Isidro, Estudios sobre Garantías Individuales, Editorial Porrúa, 1995

Constitución Política de los Estados Unidos Mexicanos Comentada. Editorial Porrúa, 1995.

Periódico Excelsior, 27 de febrero de 2006.

Seminario Judicial de la Federación.

http://www.dossierpolitico.com/vernoticiasanteriores.php?artid=16103\&relacion=dossierpolitico, p.1.

http://lahaine.org/index.php?blog=2\&p=9249 
Revista Jurídica del Departamento de Derecho

Academia de Derecho Administrativo

Tercera Época Año2. No. 3 / Julio-Diciembre 2010.

http://www.cadiz2012.es/images/secciones/constitucion/cons 1812.pdf 